\title{
Flipped Learning as a Paradigm Shift in Architectural Education
}

\author{
Ghada Mohammad Elrayies ${ }^{1}$ \\ ${ }^{1}$ Faculty of Engineering, Port Said University, Port Said, Egypt \\ Correspondence: Ghada Mohammad Elrayies, Faculty of Engineering, Port Said University, Port Said, Egypt. Tel: \\ 2-066-344-6100.E-mail: ghadaelrayies@eng.psu.edu.eg; ghadaelrayies@ymail.com
}

\author{
Received: July 26, $2016 \quad$ Accepted: September 2, $2016 \quad$ Online Published: December 24, 2016 \\ doi:10.5539/ies.v10n1p93 \\ URL: http://dx.doi.org/10.5539/ies.v10n1p93
}

\begin{abstract}
One goal of education for sustainable development is to produce creative and lifelong learners. In recent years, architectural education has been faced with the challenge of how to incorporate innovation and creativity into its programs in order to improve the human skills of its graduates in their professional practice. Establishing a basis for lifelong learning is the best way for architectural education to face its particular $21^{\text {st }}$-century global challenges. More effective methods are needed for introducing lecture-based courses (LBCs) in architectural education that can provide the skills architects need in the $21^{\text {st }}$-century. LBCs are often associated with teacher-centered methods that are incompatible with the possibility of applying these skills. This paper suggests applying the concept of flipped learning (FL) which is based on the concept of active learning and its related pedagogy, problem-based learning (PBL). The paper aims to: 1) provide a clear vision of FL, relying on its pillars of pedagogy, technology, and space; 2) investigate the challenges and opportunities faced by this concept; 3) explore the mechanisms of PBL pedagogy; 4) review the previously promulgated literature of applying PBL within the framework of FL on LBCs in the architectural curriculum; and 5) apply PBL pedagogy to LBCs in lighting and acoustics. The paper concludes by establishing a conceptual approach for the flipped classroom environment and devising a proposal of a lighting and acoustics course within a framework of PBL pedagogy.
\end{abstract}

Keywords: flipped learning, flipped classroom, architectural education, problem-based learning, lecture-based courses

\section{An Introduction to the Subject}

The United Nations' "education for sustainable development" (ESD) initiative is grounded in the $21^{\text {st }}$-century skills of initiative-taking, critical thinking, team-work, creativity, and self-direction. This UN initiative aims to help people develop their own skills, use their knowledge to make responsible decisions, and forge a path to a more sustainable future. It seeks to enable people to become creative, efficient communicators, collaborators, critical thinkers, and lifelong learners (Armstrong, 2011; Bjørke, 2014; Waas et al., 2012).

Universities are responsible for developing these skills among students and facilitating their becoming lifelong learners. Architectural education has faced the challenge of instilling innovation and creativity in students and developing their professional mindsets. Recent social changes as well as changes in the construction industry related to advancements in technology and the rapid growth of information technology demonstrate the need for more effective cross-disciplinary teamwork among industry professionals (Nicol \& Pilling, 2005; Triantafyllou, Timcenko, \& Kofoed, 2015). Architects are called to be facilitators who listen, respond, collaborate and use their skills to create responsive solutions (Brosnan, 2015). Nevertheless, many architecture graduates begin in marginal careers and have little contact with the construction industry when they leave formal study. As a result, they spend their whole careers updating their knowledge and skills. They must develop their skills in the human dimensions of professional practice and become more adaptable, flexible, and versatile practitioners throughout their careers. Architectural education plays a critical role in developing the skills and mindsets students need in professional practice and their continuing education (Nicol \& Pilling, 2005). Establishing the basis for lifelong learning is the best way for architectural education to face the global challenges of the $21^{\text {st }}$-century (ACSA). This goal, however, is inhibited by the fact that many architectural courses have traditionally been delivered as lecture-based courses (LBCs), which are often associated with teacher-based methods that inhibit the possibility of applying these $21^{\text {st }}$-century skills.

The teacher-centered learning approach (TCL) is still used extensively as the primary teaching method in higher 
educational institutions in many developing countries. In TCL, the teacher delivers knowledge in a classroom setting to students, who act as passive recipients of the information (Marks, Ketchman, Riley, Brown, \& Bilec, 2014). This teaching process transmits knowledge unilaterally. TCL may be economically effective when teaching a large number of students in a relatively short time period; nevertheless, students in this setting do not benefit from the possibility of developing sophisticated critical thinking skills. Rather, they simply listen, memorize, and repeat the delivered knowledge (Danker, 2015, pp. 171-186; Marks et al., 2014).

To transform education within the framework of sustainability, the concept of students as lifelong learners must be embraced. Teaching approaches must focus on elements relating to learning processes rather than the accumulation of knowledge. Students learn better through the use of teaching methods that are active and participatory and relate to real-life situations (Mohd-Yusof, Alwi, Sadikin, \& Abdul-Aziz, 2015; Thomas, 2009).

To engage the conceptual level of thinking, students must be active seekers, taking responsibility for their own learning. Active learning has been supported in recent years by many higher educational institutions globally, transforming classes from a traditional lecture classroom (TCR) format to a flipped classroom (FCR) (Danker, 2015, p. 171:186; Marks et al., 2014)

To speak of sustainability in architecture education involves two main issues: teaching subjects and teaching methods. Clearly, the concept of sustainability is expressed, even if rudimentarily, in many architectural curricula in the great majority of higher education institutions (Benkari, 2013). The integration of sustainability concerns in higher education is often limited to issues of greening campuses, research initiatives, and particular environmental courses/programs, while pedagogical innovation in sustainability has developed much more slowly (Armstrong, 2011; Waas et al., 2012).

This paper focuses on achieving sustainability through the pedagogical methods that architectural courses deliver to students. From author's point of view, sustainable education is the primary bridge between education and practice. In this context, the university is a facilitator that provides students with relatively little practical experience and few multidisciplinary problem-solving approaches to open-ended problems, the type generally faced in real-world practice. The research calls for changing the way LBCs are delivered to students by applying the flipped learning (FL) model and its related pedagogies. In FL, the lecture is moved outside the classroom and replaced in the classroom by activities, permitting active learning.

\section{Method}

This paper comprises two main parts. The first part is a full review of FL based on its staple pillars: pedagogy, technology, and space. The anticipated output of this review is a comprehensive understanding of the basic requirements for the establishment of a FCR. To complete the picture of FL, we will explore the mechanisms of the determined interactive pedagogy of PBL and investigate the criticisms, limitations, and opportunities encountered by such a concept. To this end, data have been collected from internet and literature resources.

The way LBCs are delivered at many universities, particularly in the developing world, does not truly fulfill the concept of FL. LBCs are often delivered based on the TCL already in use in many architectural programs. This paper suggests applying the concept of FL to LBCs. First, it is important to determine the extent of the effect and the proportion of these courses within an existing architectural program. Therefore, this paper conducted an analytical study to measure the results of these courses delivered in architecture and urban planning department, faculty of engineering, in Port Said University, together with investigating the subject areas covered by LBCs in this program. Within this area, the second part reviews the published literature with respect to LBCs and PBL in architectural programs in order to draw lessons from them with respect to PBL pedagogy. This section concludes with a theoretical proposal for a lighting and acoustics course based on PBL pedagogy, as taught by the author for more than 5 years.

\section{FL Background Information}

In the FCR, students gain their first exposure to new material outside of class via lecture videos, and then use class time to do application, analysis, synthesis, and/or evaluation of the concepts with the assistance of their peers and instructor, through problem-solving, discussion, or debates (Brame, 2013). FL is based on active learning, which itself is built on a student-centered approach that emphasizes learning by doing (Uskov, Howlett, \& Jain, 2015). Through FL, students are more interactive and engaged in learning through application and practice. Not only do students construct their own knowledge as a result of their interactions with their environment but they also participate in the process of constructing knowledge within their learning community, as the concept of FCRs places the primary responsibility for learning on students. Active learning creates face-to-face time with much deeper interaction between the teacher and students as they participate, interact with 
case studies, and discuss problems. Students reach the highest level of learning when they create individual solutions, applying the materials in a way that makes sense to them. In the FCR, the role of the instructor is to aid students, in addition to students' helping each other, a model known as peer-based learning (Danker, 2015). In FL, the instructor begins with the expected results and the intended learning outcomes (ILOs), rather than the content. This design concept is called Backwards Design (Bjørke, 2014).

The first exposure to material outside of class occurs via lecture videos, PowerPoint presentations with voice-over, and/or printable PowerPoint slides. These lecture videos can be prepared through screencasting and provided on the instructor's YouTube channel, or found online from YouTube, the Khan Academy, MIT's OpenCourseWare, MOOC platforms like Coursera, or other similar sources (Brame, 2013). Watching lecture videos at home has advantages: students control the media they view and can review the parts that they have misunderstood or been particularly interested in (Danker, 2015). During FCR, the instructor limits the time he or she lectures and increases the time students spend solving interesting problems. The instructor circulates among the students to check in on their understanding, answer their questions, and motivate them to think more deeply (Derekbruff, 2012). Figure 1 illustrates the difference between the FL model and the traditional learning (TL) model.

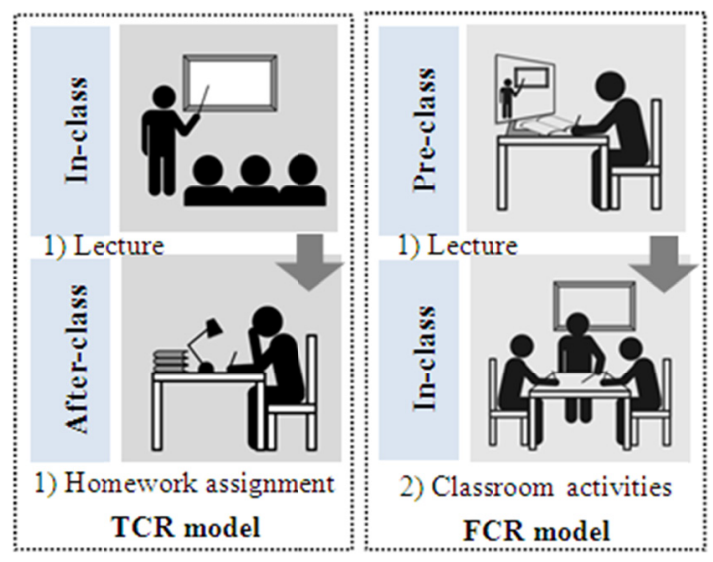

Figure 1.TCR versus FCR

\subsection{Key Elements of FL Environment}

Changing a new classroom design from a traditional concept to FCR requires integrating the three key elements of a successful learning environment: pedagogy, technology, and space (Steelcase, 2015). Every element will be discussed in the following section.

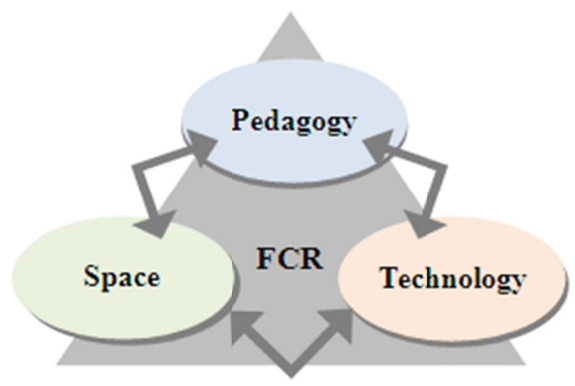

Figure 2. The three related key elements of FCR. Source: (Steelcase, 2015)

\subsubsection{Pedagogy}

FL is grounded in the experience of active learning. The instructional techniques of active learning are 
problem-based learning (PBL) and peer-learning (Danker, 2015). The PBL method has been used in teaching for more than 40 years across various disciplines, such as medicine, architecture, engineering, economics, law, and mathematics. In this method, students are given problems based on practical examples from the real world and assigned the task of finding solutions to them as a group. In order to solve the problems, students must gain new knowledge; as a result, students learn both inquiry skills and problem-solving skills. In PBL, it is the students, not the instructor, who are responsible for searching for information in various resources and determining which information and analyses are needed to resolve the problem. The PBL method also supports life-long-learning, as graduates, in their professional practice, often need to update their knowledge to keep pace with rapid development of their field. As PBL involves teamwork, it fosters the development of communication and collaboration within a simulated professional environment. Therefore, PBL and peer learning are often related. PBL helps students develop skills in holistic thinking, flexible knowledge, effective collaboration, self-directed learning, and effective problem-solving (Franssila, 2007; Steinemann, 2003; Thomas, 2009; Triantafyllou, 2015).

As supported by the theory of (Thomas, 2009), the development of thinking in PBL is the critical element in education related to sustainability.

\section{a) Mechanism of PBL process}

In PBL, the role of the instructor is to organize the process. He or she provides students with the stimulus (the actual problem or the case to be solved). He or she controls the process, guides the students, and provides them with advice and supplementary concepts when necessary. Therefore, the instructor's role is best described as that of an active listener. The number of students in the PBL group ranges between 5 and 8 . In each group, one student works as a discussion leader and another as a secretary. These two roles are rotated regularly among the students in the group. The discussion leader manages and activates the roles of the rest of the students. He or she analyzes and summarizes the students' points and opinions and asks questions to ensure each student's participation. The role of the secretary is to make notes about the discussions during the learning process. The secretary takes notes that are essential for the next step of the PBL process. The secretary can use the whiteboards to lead the discussion during PBL. The role of the other students is to participate in discussions and offer their opinions and knowledge of the subject for the benefit of the whole group (see Figure 3 ). They must also learn the skill of good listening (Franssila, 2007).

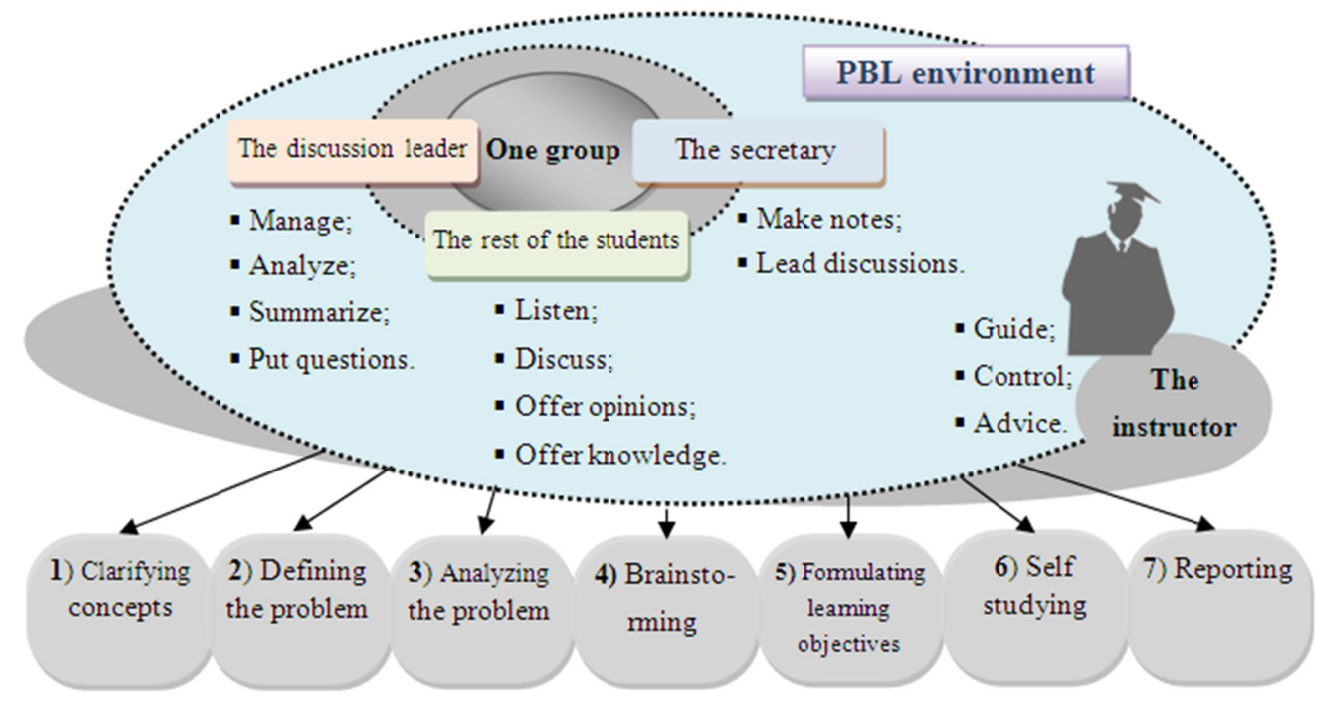

Figure 3.The roles of the participants in the PBL environment, and the steps of PBL. Source: Drawn by the author from (Franssila, 2007)

\subsubsection{Technology}

As a consequence of streaming digital technology, today's students have more opportunities than ever before to use digital electronic products, such as personal computers, tablets, and smart phones with Internet applications (Tsai, Shen, \& Lu, 2015). Today's students are adept with technology. They are comfortable using text messaging, Google, and social networking. They consider the Internet, not the library, their information universe. 
They collect, analyze, display, and disseminate knowledge using IT (Lomas \& Oblinger, 2006; Oblinger, 2006). Unfortunately, their interest about technology sometimes simply revolves around playing games or browsing social media. Tsai et al. (2015) stated that the time spent by graduate students in the United States on computer games, email, and social media is almost twice the time they spend studying. The positive side of this phenomena, however, is that there are many opportunities for online learning (Tsai et al., 2015). Online learning has begun to emerge in higher education because it provides flexible, cost-effective access to content and instruction at any time and from any place, in addition to the benefits of asynchronous discourses over synchronous-type discourses (Castle \& McGuire, 2010). The FCR shows a positive use of the technology and the Internet (Tsai et al., 2015).

In higher education, it would be difficult to identify a discipline that does not benefit from the aid of IT (Oblinger, 2006). The integration of information technology into higher education learning environments plays an important role in preparing students for the $21^{\text {st }}$-century labor market. As rapidly advancing information technology transforms society and the economy and social trends call for productivity, competition, career preparation, and teaching and learning enhancement, universities should embrace their role preparing students for lifelong learning (Callahan, 2004).

FCRs' design demands both digital and analog tools; media-equipped classrooms with both analog and digital connections are critical (PrincetonUniversity, 2013). Analog tools alone are becoming obsolete as the AV/IT (Audiovisual/Information Technology) world undergoes a revolution.

AV/IT supports the flow of information between students and the instructor. The locations and arrangements of students and instructor determine the kinds of technologies that best support the various interactions. These interactions include: 1) individuals, 2) small groups, 3) large groups, 4) the whole class, and 5) multi-modal layouts (a combination of two or more of these configurations within the same space). Digital tools include equipment such as digital HDMI (High-Definition Multimedia Interface) connections, which replace VGA analog connections, and HDVC (High-Definition Video Conference), which allows teams in remote locations to connect to the host classroom. Such digital tools include the use of BYODs (Bring Your Own Device), such as laptops, tablets, and smart phones. FCRs require mobile displays to accommodate the mobility of students and information among the class, as when a small group shares their work with a larger group. The Mediascape tools were developed to address this need. This digital tool supports remote collaboration, digital design presentations, and lecturing via digital media. One possible solution to limited classroom areas lacking individual work spaces is to provide sets of noise-canceling headphones for student use (Bergmann \& Sams, 2014; Gee, 2006; PrincetonUniversity, 2013; Steelcase, 2015).

The infrastructure installations (in ceilings, walls, and floors) related to such technologies should include easily moved and reconfigured furniture, such as seats, tables, and instructor lecterns that support different teaching and learning styles (PrincetonUniversity, 2015). Power and data access and location should be mobile as possible (Gee, 2006). To support the infrastructure of these digital tools, wireless networks are needed, with enough capacity to accommodate the number of students on the network at any time. Power adequate to support numerous devices is also necessary. Although integrating digital connections is initially expensive, their cost over time is considerably less so (PrincetonUniversity, 2013).

Analog tools, however, are also necessary in FCRs. Whiteboards and either fixed or huddle wall track allow information to remain visible to students extending the collaboration to vertical surface (Steelcase, 2015).

\subsubsection{Space}

There is no doubt that classroom design has a direct effect on learning, the central activity of universities (Oblinger, 2006). A study conducted by a team of Steelcase Education researchers in collaboration with academic researchers in Canada and the United States (2015) found that classroom design influences student engagement, which is in turn widely recognized as a strong indicator of student success. They found that classroom design that supports active learning increases students' engagement when compared to TCR, with its row-by-column seating. The majority of classrooms in use today were built for conventional stand-and-deliver, sit-and-listen pedagogy in a passive learning environment. Inflexible layouts and immobile furniture designed for the one-way transmission of information cannot support active learning or collaboration, as they inhibit interaction among the students, the instructor, and the content (see Figure 4). In various active learning pedagogies like PBL and peer learning, where students must connect, share information, and discuss solutions (Pearlman, 2013; Steelcase, 2015), classrooms need the flexibility to adapt to different learning preferences. Furthermore, classrooms must support quick transitions between learning modes, and at the same time support digital tools for student engagement. Every space can be an interactive learning space if it is designed to support 
the pedagogy and technology and it allows instructors to move among student groups, providing real-time feedback, assessment, and direction for students in peer-to-peer learning (Steelcase, 2015).

Learners' mindsets also influence the environment of the learning space. Today's students favor active and participatory learning, a learning style that may not be easily reconciled with sitting in a lecture hall in chairs fixed to the floor. Today's students are highly social. They find great value in face-to-face interactions and want faculty to promote them (Oblinger, 2006). As both form and function should be investigated, considerations should be made of pedagogical style, the predictability of the layout, the location of windows and lighting sources, furniture placement, and the use and location of projection screens (PrincetonUniversity, 2013).

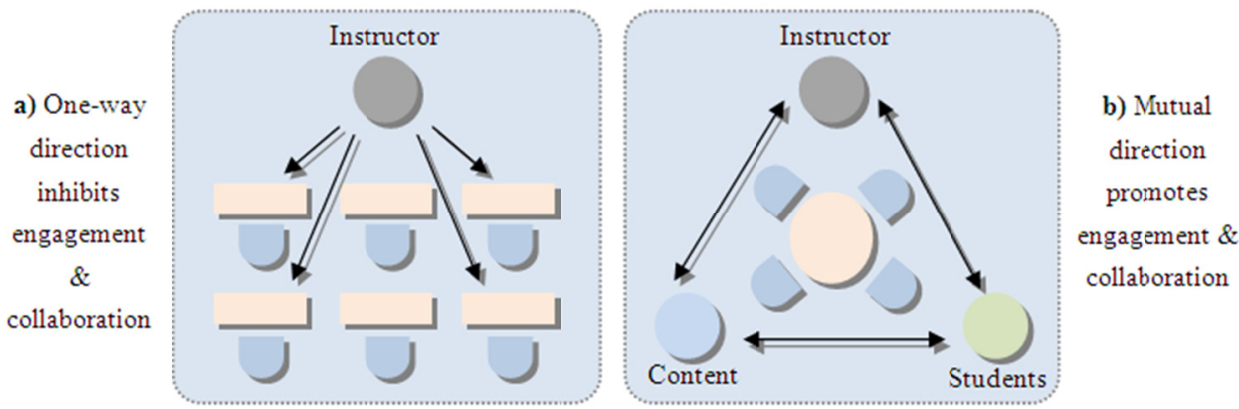

Figure 4. Passive learning classroom (a) versus active learning classroom (b)

In order to predict the proper space design strategies that are compatible with the FCR concept, the author conducted an analytical study of classroom configurations designed by Steelcase Education, generated by mixing and matching various core classroom elements (furniture, technological equipment, displaying screens) to fit different spatial environments (lecture halls, studios, labs, etc). The designs were studied according to core classroom elements related to the three key elements of the FCR learning environment: pedagogy, technology, and space. The indicated classroom configurations can be found at (Steelcase, 2015).

Table 1. The core classroom elements related to the three key elements of the learning environment. Source: author after: (Gee, 2006; PrincetonUniversity, 2013; Steelcase, 2015)

\begin{tabular}{|c|c|}
\hline Key elements of the FCR environment & Core classroom elements \\
\hline \multirow{8}{*}{ Pedagogy style } & Lecture \\
\hline & $\underline{\text { Small-group work }}$ \\
\hline & Large-group work \\
\hline & Individual work \\
\hline & Class discussion \\
\hline & Activity \\
\hline & Videoconferencing \\
\hline & Decentralized instruction \\
\hline \multirow{6}{*}{ Technology } & Vertical and horizontal display surfaces \\
\hline & Access to BYOD \\
\hline & Wireless Projectors \\
\hline & Huddle wall track whiteboards \\
\hline & Mediascape \\
\hline & Mediascape with HDVC \\
\hline \multirow{6}{*}{ Space } & Visual and physical access \\
\hline & Clear sightlines to digital and analog content \\
\hline & Quick transition among various learning styles \\
\hline & Large space to accommodate various teaching styles \\
\hline & Modular furniture \\
\hline & Swivel seating \\
\hline
\end{tabular}


The following findings were observed:

1. Classes that allow the transition among many learning styles (convertibility/flexibility) are more favorable than classes with fixed multi-learning zones. The convertible classroom is cost-effective, besides it does not need much space.

2. Modular furniture accommodates various learning styles, as it allows for individual work as well as collaboration. To this end, the split-table is easily assembled and separated. Swivel seating allows versatility and provides students with clear and constant sightlines to digital and analog content.

3. Multi-modal configuration (multiple configurations in the same space at the same time) may suit large classrooms, as it requires a larger area.

4. Mediascape enables groups to share their work and collaborate on projects digitally; in addition, Mediascape with HDVC (high-definition video conference) connects distant classrooms. Mediascape can be installed in most classroom designs that are equipped with power and data access.

5. With respect to the previous considerations, a combination of Node Classroom and Media-Lab represents a good classroom design that likely fits the FCR concept. Furthermore, movable and free Mediascape tools can be provided in such a design.

6. As FCR requires multiple display screens, both digital and analog, screens should be placed strategically to facilitate clear sightlines and lighting. Figure 5 illustrates the use of FCR within a framework of its three pillars (pedagogy, space, and technology).

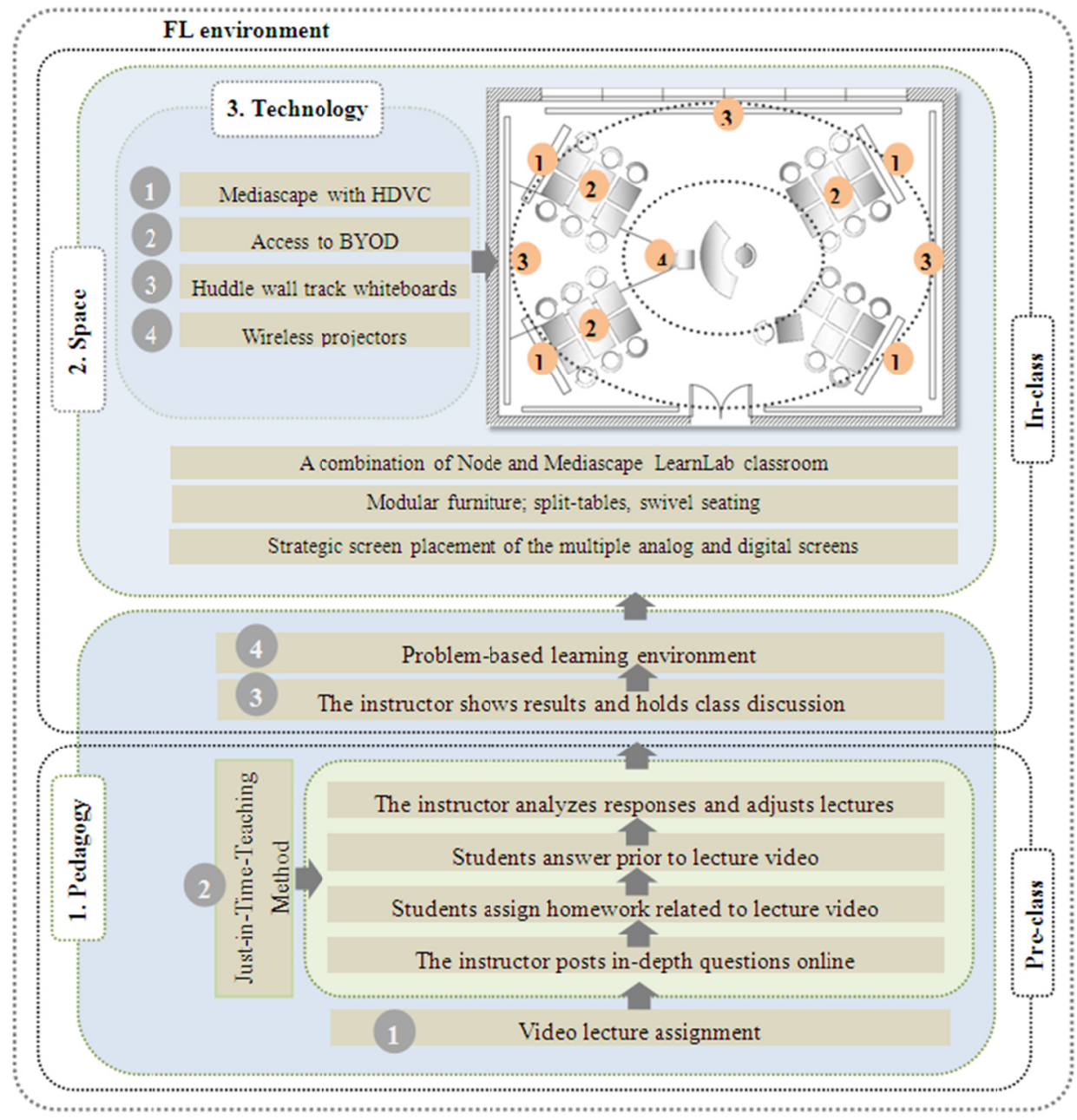

Figure 5.A visualization of FCR within a framework of its three pillars 


\section{Challenges Facing Flipped Learning Model and Opportunities}

Critics have argued that there are some drawbacks to the FCR model. This paper addresses these drawbacks and investigates their potential solutions. Some common drawbacks mentioned include:

1. Not all students completing their assignments (watching lecture videos) before class

2. Teachers' concerns about the diminishment of their role (Triantafyllou, 2015)

3. Students' skipping class and only watching the recorded lecture videos at home (HanoverResearch, 2012)

\section{Accessibility of online lectures}

5. increased demand on instructors to integrate out-of-class and in-class activities (Kerr, 2015)

To address the first criticism, an assignment-based model, called Just-in-Time-Teaching method (JiTT), was proposed to hold students accountable for the pre-class assignment. In that approach, students are expected to complete worksheets (writing, problems, etc.) and/or online quizzes before class time. The instructor posts in-depth questions online, and the students are graded on how well they use the lecture video in their answers. The students' answers are delivered to the instructor a few hours before class, allowing the instructor to analyze the responses and modify their lectures as needed. The instructor can use class activities to focus on the elements with which students are struggling and students can identify areas where they need help, and clarify their thinking about a subject, thereby producing richer in-class discussions. Such a method also provides valuable insight into student thinking. Providing students with an incentive to prepare their tasks before class is important, as "points" are part of the common language of undergraduates. Automatically grading pre-class worksheets and online quizzes help both instructor and students (Brame, 2013).

As for the second criticism, the argument that instructional videos will replace the instructor's role is misguided. Skilled professional educators in the flipped model are more important and necessary than ever. They manage when and how to shift the instruction from lecture mode to discussion mode, from individual work to group work, and from one pedagogy to another. Professional educators know how to use the affordances of the flipped model to help students gain conceptual understanding. Professional educators continually observe their students during class time, provide them with feedback relevant at the moment, continuously assess their work, and control classroom chaos. Despite this, they do take on fewer roles in the FCR (Hamdan, McKnight, McKnight, \& Arfstrom, 2013).

In response to the third criticism, despite a common fear among instructors that access to recorded lectures will affect students' attendance in class, surveys at various American and British institutions have indicated that access to lecture podcasts generally does not lead to student absences. In another study, students asserted that attending class offers opportunities for interaction within a structured learning environment (HanoverResearch, 2012).

As for the fourth criticism, since activities outside the lecture hall rely on technology, lecture videos should be made available to students through various points of access, like laptops, tablet computers, smart phones and DVD players. In areas with no access to the Internet, lectures can be downloaded onto DVDs and USB drives. The faculty also plays a role in overcoming this complication by providing lectures on library and lab computers, which students can use to view the videos before class (Danker, 2015).

Finally, to address the fifth criticism, it is true that quality preparation of lecture videos is time consuming and that the careful design and integration of out-of-class and in-class activities requires effort. Instructors' in-class time, however, is made easier, as they spend class time simply walking around and observing students, advising and guiding them. Danker, (2015) argued that the additional effort needed could be mitigated by approaching the model slowly (Danker, 2015).

\section{Employing PBL for LBCs in Architectural Curriculum}

\subsection{Drawbacks of LBC Pedagogy}

The major disadvantage of lecturing is that it is often a waste of time. Students store the information in their short-term memory and promptly forget it after the exam (Bjørke, 2014). According to Miller, lectures account for only about $5 \%$ of what the average student retains (Miller, 2008). Learners who work on problem-solving with peers in class apply higher-level thinking skills than do learners who merely listen passively to an in-class lecture (Bjørke, 2014).

Architecture is an apprenticeship-based career. The balance between theory and practice in architectural education has been discussed for centuries. Educators argue that architecture institutions should educate students 
how to analyze, design, think, and explore a variety of solutions, not simply how to do something correctly (ArchitectureWiwik, 15 July 2013). A study conducted by Ashraf Salama (2010) found that the integration of interactive learning mechanisms into architectural lecture courses, such as theory courses, helps students to maintain control over their learning while activating their understanding of the knowledge delivered in the typical lecture format (Salama, 2010).

LBCs in an architectural program account for a considerable share of the entire program. The author analyzed the architectural program in Architecture and Urban Planning Department in the Faculty of Engineering at Port Said University. It was found that LBCs account for about $33.3 \%$ of both the first and second years of the program, and $25 \%$ in the third and fourth years. LBCs account for about $30 \%$ of the entire program. The subject areas covered by LBCs are human sciences, theory and history, and technology and science (such as building technology and lighting and acoustics). The author recommends that these LBCs be flipped in order to achieve the expected learning outcomes that target teamwork, self-direction, critical thinking, and creativity skills, which qualify graduates to be lifelong learners. Grounded in the background of PBL indicated in this paper, Figure 6 illustrates the LBC within a framework of PBL pedagogy. The literature related to applying PBL in LBCs in architectural education will be reviewed in order to better understand the effectiveness, execution, and mechanisms of PBL in such courses. It will be summarized in the next section.

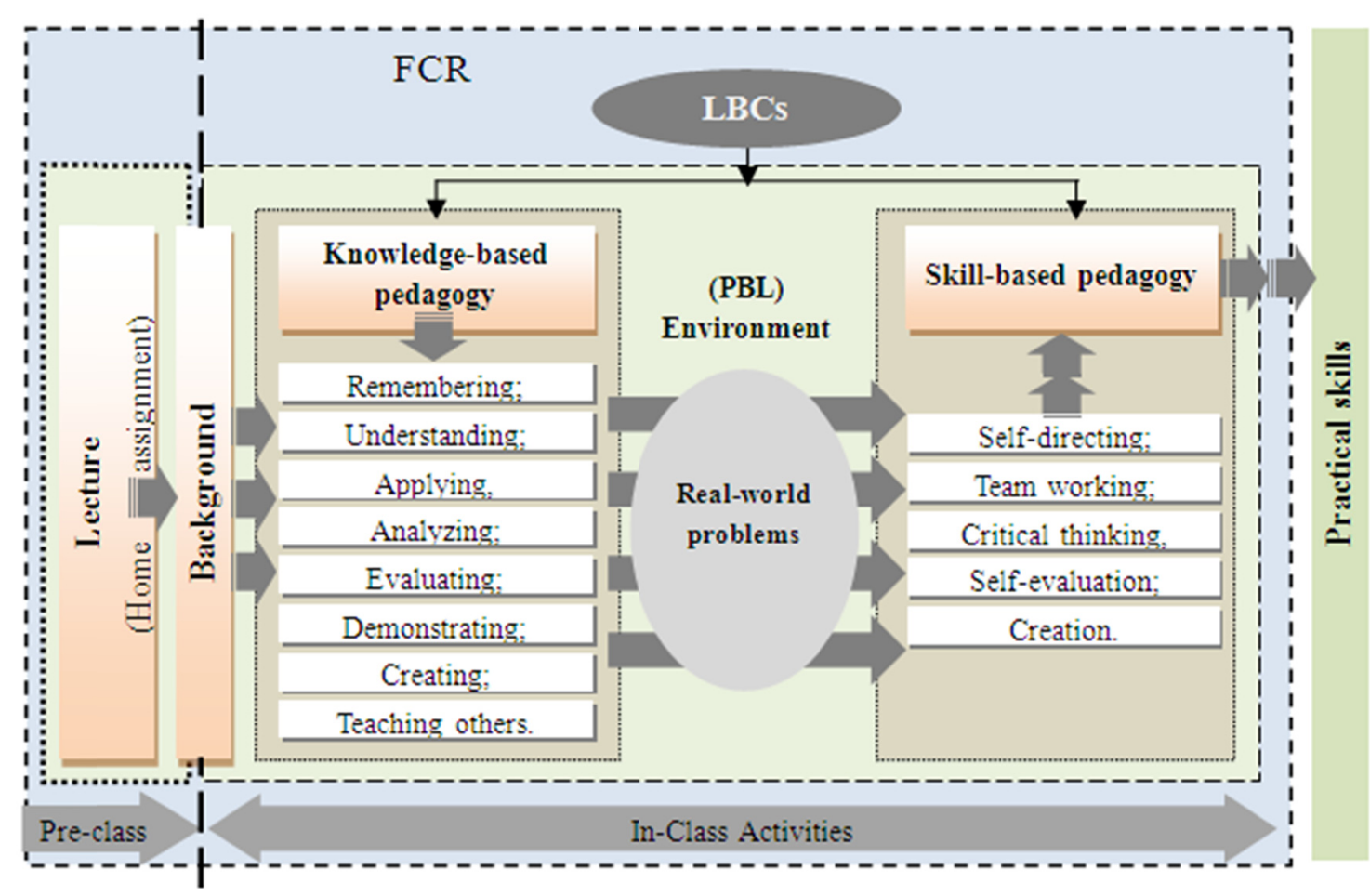

Figure 6. LBC in a framework of PBL pedagogy. Source: author after: (Bjørke, 2014; Galford, Hawkins, \& Hertweck, 2015; Salama, 2005)

\section{Literature Review of Flipping Architectural LBCs within a Framework of PBL}

The literature on the effectiveness and execution of a PBL environment in architectural education, particularly in LBCs, is inadequate despite the fact that the concept of PBL was developed more than 40 years ago. Via an online search, this paper compiled the available literature related to that concern and relevant to the paper's scope of architectural education, FL, BPL, and LBCs. The experiences of two courses will be reviewed.

\subsection{Sustainable Urban Development (SUD) Course}

Steinemann examined a unique experience in his SUD course within a framework of the PBL environment. In his experience, students identify a sustainability problem on their campus and then develop a sustainability project to address it. Steinemann developed a course syllabus including course objectives, background about the pedagogy used (PBL), and the two major expected products (the "project" and the "lessons learned"). He 
identified the cognitive levels during the PBL in the form of discussion and written reports. He designed a report format with specific topics related to the project and another regarding lessons learned. The syllabus includes the main project's topics. The student evaluation system is another significant part of the PBL applied in this. Steinemann stated that the evaluation system is important because it provides the instructor with feedback, assesses student progress, and enables the instructor to adjust the course. It involves regular questions posed by the instructor, weekly student self-evaluations, weekly open group discussions recorded by the instructor, and the two final reports on the lessons learned and the project. Throughout his experience, he reported students' appreciation for working on real-world projects and having ownership over the project.

In Steinemann's experience, the PBL method provides students with skills for acquiring, analyzing, and applying knowledge. In addition, they simulate professional practice and gain how to deal with stakeholders and interdisciplinary problems. They acquire professional communication skills through face-to-face experience. Applying PBL in teaching his course linked community with education through students projects.

The challenges he faced are summarized as:

1. Striking a balance between giving students complete responsibility to solve the problems and giving them feedback and guidance needed to guide the course correctly.

2. Restrictions on the students' ability to implement their projects due to the limited duration of the semester. (Students' project reports, including analysis and recommendations, may used later by decision makers to implement previous projects, however.)

3. Students' loss of interest and feelings of discouragement due to seeing few results from their considerable effort and time. Steinemann found that feeling successful and encouraged comes from discussing their project benefits, cost savings, and feasibility through involvement with stakeholders.

4. The additional time and effort of teaching a PBL course compared with a LBC, in terms of preparation, management, and assessment. This is in addition to the additional effort needed from the instructor to work with the faculty administrators and obtain their support (Steinemann, 2003).

\subsection{Acoustics, and Lighting Courses}

Worcester Polytechnic Institute (WPI) has integrated the three pedagogies of project-based learning, computer-based learning, and lecture-based learning in two of its courses, Acoustics and Lighting. Students were assigned the task of solving real-life problems with real buildings in their classes.

In the Acoustics course, the first five weeks of the semester were devoted to intensive lecturing on the basic principles of acoustics in tandem with assessment studies, while the last two weeks were dedicated to project-based and computer-based methods. The students' evaluation system involved submitting two reports about the course-related topics and a final report about the visual simulation and the retrofitting of real campus classrooms in different hypothetical situations. They investigated and analyzed the current status of the buildings using CATT, then re-designed the spaces according to the results they found. Another critical assignment was a poster presentation of the final project presented to the departmental community. This enabled students to demonstrate their projects to, compare themselves with, and assess each other.

In the students' experience delivering the Lighting course, two weeks were devoted to lectures on the basic principles of the subject. The students' evaluation system relied on three assignments: the first was to solve real-world problems and the other two were to analyze, measure, simulate, and solve problem scenarios of a real-world museum in order to propose the optimal design to meet the museum's lighting energy-saving needs. They investigated and analyzed the current status of the building using DIALux. Similarly to the acoustics course, students prepared a poster presentation demonstrating their projects for the faculty, staff, and public. In a fostering initiative, the museum director shared students' posters on the museum website (Berardi, 2013).

Berdari (2013) reported on the students' design in real cases of long-term sustainability issues in both acoustics and lighting environments. Such simulations enabled students to develop their professional mindsets, as the projects fostered their skills of critical evaluation, self-assessment, and creativity, as well as developing their awareness of the relationship between physical principles and person perception. The progress of students' performance in this experience highlights the role of real-world problems in engaging students in the issue of real buildings and making sense of their related environmental and energy problems.

\section{A Practical Guide to Applying the FL Model to Lighting and Acoustics Course}

Grounded in the previous literature, in the PBL environment there are two main issues: the creation of problems related to the course's topics, and the students' evaluation system. The design of these problems is critical in 
ensuring the course's outcomes. These problems should be included in the course syllabus. They can be included in the table of contents, before the lecture topics, in order to cover the different modules. The course instructor should design the problems, which should be linked to the application of knowledge to real buildings. Turning real-life issues into topics for student projects is a process that should involve the institution's stakeholders and the departmental community; in fact, community involvement is at the heart of the PBL process. The simulation of a practical environment for the student during his or her formal study in architecture is critical in preparing students for professional practice.

With regard to the students' evaluation system, regular weekly assessment is needed in order to provide the instructor with sufficient feedback to adjust the lectures and ensure that the PBL process is unfolding appropriately. In tandem with final reports and a final project, students can assess themselves and each other, which consequently helps develop their critical evaluation and self-assessment skills.

For a course about lighting and acoustics, computer-based learning methods and field visits are essential in raising awareness of real-world buildings and related sustainability issues. The next section will introduce the author's proposal for lighting and acoustics course based on PBL pedagogy.

Before beginning a PBL class, in order to ensure learning outcomes and the students' motivation, students must be prepared to adapt to the new pedagogical model. This preparation begins by defining the PBL environment in an initial comprehensive tutorial session (Smith, 2005).

The lighting and acoustics course, according to the architectural department in the faculty of engineering at Port Said University, is a LBC delivered to second-year undergraduate students 3 hours per week. The basis of the course is solving simple exercises about related topics on virtual spaces. The lecture time is divided between lecturing and skills-application time. Lecture time often isn't enough for the application, so students complete their assignments at home in a form of worksheets. The author suggests delivering the recorded lectures online via a Facebook group to the students weekly. Lectures could be delivered even PowerPoint or PDF formats. The author's proposal of classroom activities, might include solving real-world problems and evaluating scenarios. The cognitive levels that have been considered during the design process of the problems are: demonstration, discussion, practice-doing, and teaching others. The expected skills in that experience are: teamwork, self-assessment, critical thinking, and creation. Table 2 shows the pre-class assignment (home lectures) and the corresponding PBL problems (in-class activities) distributed over the 14 weeks of the semester as a proposal for applying the integrated PBL FL model in the Lighting and Acoustics course.

As PBL and Project-Based Learning are often associated (Raine \& Symons, 2005), the $15^{\text {th }}$ week is devoted to project-based learning.

Table 2.A proposal for PBL-related Exercises in a Lighting and Acoustics Course

\begin{tabular}{|c|c|c|}
\hline $\begin{array}{l}\frac{4}{0} \\
3\end{array}$ & $\begin{array}{l}\text { Pre-class assignment } \\
\text { (Home lectures) }\end{array}$ & $\begin{array}{l}\text { In-class activities } \\
\text { PBL problem } \\
\text { (Performed within groups according to PBL mechanisms) }\end{array}$ \\
\hline 1 & $\begin{array}{l}\text { 1. Introduction } \\
\text { 1.1. Definition of light } \\
\text { 1.2. Benefits of using daylight in } \\
\text { illuminating buildings }\end{array}$ & $\begin{array}{l}\text { 1. Students experience multiple spaces with various lighting environments in their } \\
\text { building and prepare a report about their subjective measurements. } \\
\text { 2. Students could calculate the expected energy and potential cost savings of } \\
\text { replacing lamps with windows. } \\
\text { [Answers could be presented on boards or digitally via display screens, such as } \\
\text { Mediascape. } \\
\text { General discussion related to the pre-class assignment (lecture video)]. }\end{array}$ \\
\hline 2 & $\begin{array}{l}\text { 1.3. Eye and Sight (Visual Perception), eye } \\
\text { adaptation and accommodation, and visual } \\
\text { comfort. }\end{array}$ & $\begin{array}{l}\text { 1. How occupants' visual comfort in the classroom environment be enhanced? } \\
\text { [Students suggest multiple solutions based on lectures and Internet searches]. } \\
\text { [Answers could be presented on boards or digitally via Mediascape]. }\end{array}$ \\
\hline 3 & 1.4. Designing with Daylight & $\begin{array}{l}\text { 1. How can the faculty building be modified using various daylight strategies? } \\
\text { Students can conduct research and prepare a presentation about such strategies. } \\
\text { [Answers could be presented on boards or digitally via Mediascape]. }\end{array}$ \\
\hline
\end{tabular}




\section{Daylight Factor}

2.1. Measurement of sky component for 4 windows

2.2. Measurement of externally reflected component for window

2.3. Measurement of internally reflected 5 component for wall windows

2.4. Measurement of daylight factor

3. Glare

6 3.1. Levels of glare

3.2. Calculation of the glare index

$7 \quad$ Mid-term exam

4. Designing with lamps

4.1. Types of Lamps

8 4.2. Measurements of the required numbers of lamps in a space

5. Introduction of Acoustics

5.1. Behavioral characteristics of sound

9

5.2. Wavelength, frequency \& intensity

5.3. Distribution of sound: transmission, reflection and absorption

5.4. The Ear and perception of sound

\section{Design of Auditoriums}

10

\subsection{Open-air cinema design:}

Factors affecting open-air cinema design: site, wind, temperature, and humidity.

6.2. Techniques of closed auditoriums design (e.g., speech halls, cinema and music

11 halls, opera and theatres) : Ceiling, Plan Shape, Side Walls, Rare Wall, Balcony Window

7. Sound Absorption Materials

7.1. Conditions for choosing absorption materials

7.2. Types of absorption materials
1. Apply physical measurements of SC and ERC to the classroom environment

2. Apply the same problem with various windows dimensions and location to a specific space among groups and comparing the results

1. Apply both manual and metric physical measurements of DF for the classroom environment

2. Apply the same problem with various windows dimensions and location for a specific space amongst groups and comparing the results

1. Apply hand-held physical measurements of the glare index to various points in the classroom environment

2. Apply hand-held physical measurements of the glare index to various windows cases in different spaces in the facility

1. Apply both manual and metric measurements of required number of lamps required to illuminate real-world spaces (classroom, library, etc.)

2. Check whether ceiling light fixtures will be adequate to illuminate one's desk. Is this an appropriate value? [Every group will survey factors they need to perform analysis.]

3. Compare daylight measurements with electric lighting and give notes

1. Select a large space inside your building and observe and evaluate the acoustics in this space when it is empty and when it is full of people. Discuss the acoustics with the building's users to learn more about their impression [Groups prepare a report to address their opinions about the architectural design of the space from an acoustics point of view.]

[This survey represents an introduction and brainstorming session for the design of auditorium halls.]

2. Perform metric measurements of the sound pressure level of different spaces in your building, and give notes.

1. Identify noise sources on your campus and suggest measurements to avoid noise.

2. How does wind alter sound propagation? Support your answer with examples.

3. How can temperature affect sound propagation? Support your answer with examples.

4. How does humidity alter sound propagation? Support your answer with examples.

[Every group can tackle one problem, and then the entire class will share their results.]

1. Analyze a large hall in your faculty with respect to ceiling, plan shape, side walls, rare wall, and balcony window if presented. Discuss the acoustics with the building's users to learn more about their impression.

2. A field trip to a large auditorium is required (e.g., the Egyptian Opera House). There, students perform subjective measurements paired with concurrent physical sound measurements ( $\mathrm{dB}$, taken with handheld devices).

1. Conduct a research on types of absorption materials and criteria for preference.

2. Deduce the factors influencing the acoustic performance of sound-absorbing materials 
7.3. Absorption coefficient

\begin{tabular}{|c|c|c|}
\hline 13 & $\begin{array}{l}\text { 7.4. Measurements of } \mathrm{R}_{\mathrm{t} 60} \text { (Reverberation } \\
\text { time) }\end{array}$ & Perform physical sound measurements for $\mathrm{R}_{\mathrm{t} 60}$ in a series of spaces on campus \\
\hline \multirow{4}{*}{14} & & 1. Develop acoustical performance criteria based on the evaluation and analysis of a \\
\hline & 8.1. Kinds of noise & space in your building \\
\hline & 8.2. Air-borne noise & 2. Refine the design of the space to ensure the successful application of the design \\
\hline & 8.3. Structure-borne noise & criteria \\
\hline 15 & Project-based Learning & $\begin{array}{l}\text { Students will be expected to prepare a written design analysis of a specific visual } \\
\text { and acoustical environment within the campus. Performance specifications for the } \\
\text { space will be established, and each student will be required to design, and/or refine } \\
\text { an existing design of the selected space. }\end{array}$ \\
\hline
\end{tabular}

\section{Conclusion}

This paper discloses an approach to transforming the present higher educational pedagogical methods within a framework of FL. The FCR model is structured on three related and correlated pillars: pedagogy, technology, and space. The pedagogy is promoted by technology and enabled and motivated by space. Technology is established by space, and space is extended by technology. Figure 7 summarizes the core principles of the FCR.

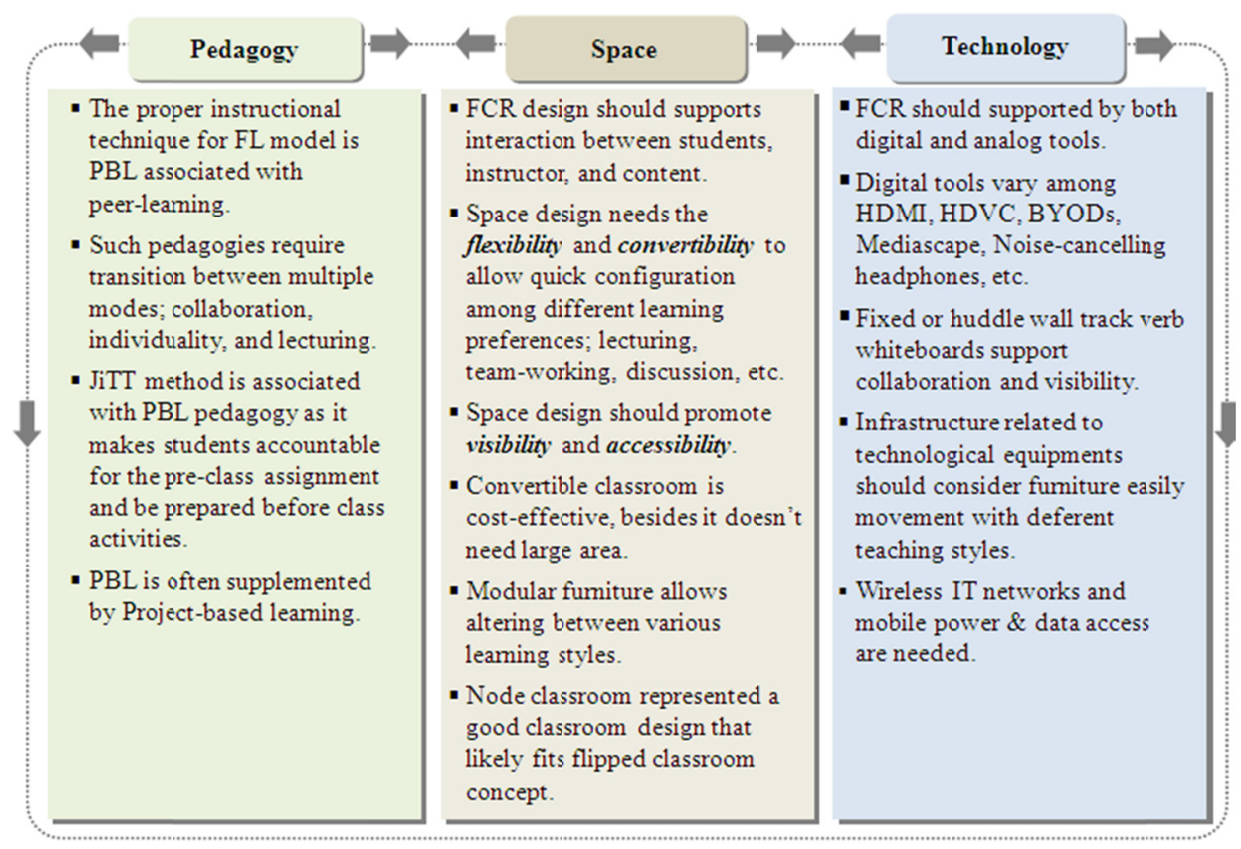

Figure 7. Theoretical framework of the FCR environment

Certain prospects of the FL concept cannot be dismissed. The concept of FL ensures student engagement and collaboration. It expands the time devoted to activities and application of learned principles. Establishing the FCR requires complementary infrastructure, both physical and human. The instructor alone cannot flip his or her classroom without the support of the institution's stakeholders. The physical infrastructure, as indicated previously, requires specific wiring to support the technology. This includes the Internet, technological equipment, and furnishings. Human infrastructure includes establishing the concept of FL among faculty members and providing them with an adequate background on its related pedagogies. Applying such pedagogies implies the conscious design of related real-world problems and proper student assessment methods.

TCR can be easily transformed into FCR, depending on available infrastructure resources. As mentioned previously, the cost of FCR is higher than TCR with regard to its technological, space, and furniture demands; 
nevertheless, there are very few respects in which we can transform TCR to FCR. A conventional computer laboratory can act as a FCR, as it meets the minimum infrastructure requirements, such as Internet access and BYODs.

\section{Recommendations and Further work}

The creation of PBL pedagogy in an integrated FL environment delivering a lighting and acoustics course establishes students' ability to work within an overall creative architectural design environment. In the lighting and acoustics course addressed in this paper, computer-based technology should be included. 3D modeling and simulation software are essential in such courses based in building physics. The theoretical PBL basis of this study must be executed on the ground. The next research step is to apply the experience by performing subjective analysis with a questionnaire and measure the academic achievement. That will reveal the applicability of this model and the extent to which educators can how to take advantage of such an application.

\section{References}

ACSA. Architectural Education. $\quad$ Retrieved from http://www.acsa-arch.org/resources/student-resources/overview/architectural-education

ArchitectureWiwik. (15 July 2013). Balancing Architectural Theory with Practical Education.Retrieved from http://www.architecture-wiwik.com/architecture-education-theory-vs-practice/

Armstrong, C. M. (2011).Implementing Education for Sustainable Development: The Potential Use of Time-Honored Pedagogical Practice from the Progressive Era of Education.Journal of Sustainability Education, 2.

Benkari, N. (2013). The "Sustainability" Paradigm in Architectural Education in UAE.Procedia-Social and Behavioral Sciences, 102, 601-610. doi:http://dx.doi.org/10.1016/j.sbspro.2013.10.777

Berardi, U. (2013). Acoustics and Lighting in Architectural Engineering Education: The experience of WPI. Paper presented at the 2013 ASEE Northeast Section Conference, March 14-16, 2013, Norwich University. Retrieved from http://asee-ne.org/conferences/aseene/2013/index.php/aseene/aseene2013/paper/viewFile/145/19

Bergmann, J., \& Sams, A. (2014).Flipped Learning: Gateway to Student Engagement. International Society for Technology in Education.

Bjørke, S. A. (2014). Pedagogical Approaches in Online Education.Retrieved from https://ufbutv.com/2014/02/26/pedagogical-approaches-in-online-education/

Brame, C. J. (2013). Flipping the Classroom.Retrieved from https:/cft.vanderbilt.edu/guides-sub-pages/flipping-the-classroom/

Brosnan, P. (2015). Architecture and Leadership Development.Retrieved from http://legatdesign.com/author/legatarchitects/

Callahan, J. (2004). Effects of different seating arrangements in higher education computer lab classrooms on student learning, teaching style, and classroom appraisal (Master of Interior Design Master, University of Florida).

Castle, S. R., \& McGuire, C. J. (2010). An Analysis of Student Self-Assessment of Online, Blended, and Face-To-Face Learning Environments: Implications for Sustainable Education Delivery. International Education Studies, 3(3), 36-40. http://dx.doi.org/10.5539/ies.v3n3p36

Danker, B. (2015). Using flipped classroom approach to explore deep learning in large classrooms. IAFOR Journal of Education, 3(1), 171-186. http://dx.doi.org/10.1016/j.compedu.2009.08.012

Derekbruff. (2012). The Flipped Classroom FAQ.Retrieved from http://www.cirtl.net/node/7788

Franssila, T. (2007).Developing Teaching by Implementing Problem Based Learning. Retrieved from https://publications.theseus.fi/bitstream/handle/10024/20420/jamk_1191578208_2.pdf?sequence=1

Galford, G., Hawkins, S., \& Hertweck, M. (2015). Problem-Based Learning as a Model for the Interior Design Classroom: Bridging the Skills Divide Between Academia and Practice. Interdisciplinary Journal of Problem-Based Learning, 9(2), 1-14. http://dx.doi.org/10.7771/1541-5015.1527

Gee, L. (2006). Human-Centered Design Guidelines. In D. G. Oblinger (Ed.), Learning spaces (pp. 10.11-10.13).EDUCAUSE.

Hamdan, N., McKnight, P., McKnight, K., \& Arfstrom, K. M. (2013).A Review of Flipped Learning, Flipped 
Learning Network.Retrieved from http://www.flippedlearning.org/review

HanoverResearch.(2012). Innovative Practices to Support Student Learning and Success.Retrieved from https://www.tccd.edu/documents/About\%20TCC/Institutional\%20Research/TCCD_Innovative_Practices_t o_Support_Student_Learning_and_Success.pdf

Kerr, B. (2015). The Flipped Classroom in Engineering Education: A Survey of the Research. Paper presented at the Proceedings of 2015 International Conference on Interactive Collaborative Learning (ICL),20-24 September 2015, Florence, Italy.

Lomas, C., \& Oblinger, D. G. (2006).Student Practices and their Impact on Learning Spaces. In D. G. Oblinger (Ed.), Learning spaces (pp. 5.1-5.11): EDUCAUSE.

Marks, J., Ketchman, K. J., Riley, D. R., Brown, L. R., \& Bilec, M. M. (2014).Understanding the Benefits of the Flipped Classroom in the Context of Sustainable Engineering. Paper presented at the ASEE Annual Conference and Exposition. Indianapolis, IN, ASEE.

Miller, H. (2008). Rethinking the Classroom: Spaces Designed for Active and Engaged Learning and Teaching.Retrieved http://www.hermanmiller.com/research/solution-essays/rethinking-the-classroom.html

Mohd-Yusof, K., Alwi, S. R. W., Sadikin, A. N., \& Abdul-Aziz, A. (2015).Inculcating Sustainability among First-Year Engineering Students Using Cooperative Problem-Based Learning.Sustainability in Higher Education, 67- 95.http://dx.doi.org/10.1016/B978-0-08-100367-1.00004-4

Nicol, D., \& Pilling, S. (2005). Changing Architectural Education: Towards a New Professionalism. Taylor \& Francis.

Oblinger, D. G. (2006).Space as a Change Agent. In D. G. Oblinger (Ed.), Learning spaces (Vol. 1, pp. 1.1-1.4): EDUCAUSE.

Pearlman, R. (2013). Bring on the Collaboration.Retrieved from http://ii.library.jhu.edu/category/activelearning/page/2/

PrincetonUniversity.(2013). Report of the Classroom Design Committee. Retrieved from https://www.princeton.edu/provost/space-programming-plannin/SCCD_Final_Report_RF_12-12-2013.pdf

PrincetonUniversity. (2015). Active Learning Classroom: Program.Retrieved from https://www.princeton.edu/mcgraw/Princeton-Workshop-Report-FINAL-DRAFT-pages-.pdf

Raine, D., \& Symons, S. (2005). Possibilities: A Practice Guide to Problem-Based Learning in Physics and Astronomy. The higher education academy: Physical Sciences Centre, 1,54.

Salama, A. (2005). Skill-Based/Knowledge -Based Architectural Pedagogies: An Argument for Creating Humane Environments.Paper presented at the Proceedings of 7 th International Conference of the IAHH-International Association of Humane Habitat-Enlightening Learning Environments, International Association of Humane Habitat-IAHH, Compact Disc, Mumbai, India.

Salama, A. (2010). Delivering Theory Courses in Architecture: Inquiry Based, Active, and Experiential Learning Integrated.Archnet-IJAR: International Journal of Architectural Research, 4(2-3), 278-295.

Smith, K. H. (2005). Problem-Based Learning in Architecture and Medicine: Comparing Pedagogical Models in Beginning Professional Education. Paper presented at the 21st National Conference on the Beginning Design Student, 24-26 February, College of Architecture, The University of Texas at San Antonio.

Steelcase.(2015). Active Learning Spaces.Retrieved http://www.steelcase.com/content/uploads/2015/01/V5-SE-Insights-Guide-pricing-interactive.pdf

Steinemann, A. (2003). Implementing Sustainable Development through Problem-Based Learning: Pedagogy and Practice.Journal of Professional Issues in Engineering Education and Practice, 129(4), 216-224. http://dx.doi.org/10.1061/(ASCE)1052-3928(2003)129:4(216)

Thomas, I. (2009). Critical Thinking, Transformative Learning, Sustainable Education, and Problem-Based Learning in Universities.Journal of Transformative Education, 7(3), 245-264. http://dx.doi.org/10.1177/1541344610385753

Triantafyllou, E. (2015). The Flipped Classroom: Design Considerations and Moodle. Paper presented at the Exploring Teaching for Active Learning in Engineering Education (etalee), Technical University of Denmark, Copenhagen. Retrieved from http://www.etalee.dk/assets/etalee2015_submission_5.pdf 
Triantafyllou, E., Timcenko, O., \& Kofoed, L. B. (2015).Student Behaviors and Perceptions in a Flipped Classroom: A case in undergraduate mathematics. Paper presented at the Proceedings of the Annual Conference of the European Society for Engineering Education 2015 (SEFI 2015).

Tsai, C.-W., Shen, P.-D., \& Lu, Y.-J. (2015). The Effects of Problem-Based Learning with Flipped Classroom on Elementary Students' Computing Skills: A Case Study of the Production of Ebooks. International Journal of Information and Communication Technology Education (IJICTE), 11(2), 32-40. http://dx.doi.org/10.4018/ijicte.2015040103

Uskov, V., Howlett, R. J., \& Jain, L. C. (2015).Smart Education and Smart e-Learning. Springer International Publishing.

Waas, T., Hugé, J., Ceulemans, K., Lambrechts, W., Vandenabeele, J., Lozano, R., \& Wright, T. (2012).Sustainable Higher Education.Understanding and Moving Forward.Retrieved from http://www.vub.ac.be/klimostoolkit/sites/default/files/documents/sustainable_higher_education_understandi ng_and_moving_forward_waas_et_al_.pdf

\section{Copyrights}

Copyright for this article is retained by the author(s), with first publication rights granted to the journal.

This is an open-access article distributed under the terms and conditions of the Creative Commons Attribution license (http://creativecommons.org/licenses/by/4.0/). 